\title{
Clinical Application of Three-Dimensional Quantitative Ultrasonography in Presumptive Diagnosis of Hepatic Lipidosis in Common Mynahs (Acridotheres tristis)
}

\author{
Yasamin Vali ( $\nabla$ yvali@ut.ac.ir) \\ Mohammad Molazem \\ University of Tehran

\section{Sarang Soroori \\ University of Tehran} \\ Seyed Ahmad Madani \\ University of Tehran \\ Mohammad Hassanzadeh \\ University of Tehran
}

Veterinarmedizinische Universitat Wien https://orcid.org/0000-0002-6090-0663

\section{Research article}

Keywords: Quantitative ultrasonography, Virtual Organ Computer-aided AnaLysis, Three-dimensional ultrasonography, Hepatic lipidosis, Common Mynah

Posted Date: April 17th, 2020

DOI: https://doi.org/10.21203/rs.3.rs-20199/v1

License: (c) (i) This work is licensed under a Creative Commons Attribution 4.0 International License. Read Full License 


\section{Abstract \\ Background}

Hepatic disorders are important and diverse disease entities in birds with nonspecific clinical signs. However, paraclinical examinations such as analysis of hepatic enzymes and diagnostic imaging can help evaluation of the liver changes, a definitive diagnosis is possible only with the histopathological evaluation. The aim of the present study was to determine the feasibility and capability of using three-dimensional (3D) Virtual Organ Computer-aided AnaLysis (VOCAL) ultrasonography as a noninvasive method for etiologic diagnosis of hepatomegaly in common mynah (Acridotheres tristis).

\section{Result}

Mean gray level of liver, mean gray level of muscle, and relative proportion of mean gray level of liver and muscle were calculated using VOCAL 3D-ultrasonography. Statistical analysis of mean gray level of liver and muscle, and relative proportion of gray level of liver and muscle in relation to lipidosis, iron storage, fibroplasia and hepatitis revealed that calculated proportion of mean gray levels of liver and muscle was significantly different among groups with different degrees of lipidosis. Further post-hoc analysis revealed that this proportion in the patients with no or slight lipidosis was significantly greater than the birds which suffered from moderate and severe lipidosis.

\section{Conclusion}

Application of VOCAL three-dimensional ultrasonography and evaluation of proportion of mean gray level of liver and muscle can be used as a helpful noninvasive method for diagnosis and monitoring of moderate to severe liver lipidosis in birds, but further validation and comparison with normal livers are needed in patients and normal population.

\section{Background}

Hepatic disorders are important and diverse disease entities in birds [1,2,3]. Clinical signs of avian hepatic diseases are not specific, so the etiologic diagnosis is challenging $[3,4]$. Hematological and biochemical laboratory workouts are routinely applied to asses liver damage or hepatic function in birds. Analysis of hepatic enzyme activity is a common diagnostic method for rough evaluation of hepatic diseases. Lack of standard reference ranges in different avian species, variation in individual cases, and questionable test sensitivity and specificity are limiting factors for using these biochemical tests $[3,4,5]$. In general, plasma activity of liver enzymes or evaluation of bile acids could be only an indication of non-specific hepatocyte damages or functional deficiency $[1,4,5]$. Valuable diagnostic information such as rough size of the liver can be achieved using radiographic evaluation, but it is incapable of diagnosis of the parenchymatous changes and the severity of hepatic lesions [5, 6]. Ultrasonography (US) can help us defining these changes in the liver parenchyma but the exact etiologic diagnosis is often not possible without additional cytological or histopathological examinations $[4,5]$. Postmortem pathological examination or histological evaluation of liver biopsy specimens 
are considered as the gold standard for definitive diagnosis of liver lesions [1, 4, 5]. Taking biopsy samples from severely ill and moribund patient with impaired liver functions is always risky could be life threatening in small avian patient with possible hepatic coagulopathies $[4,5]$. Therefore, development of noninvasive clinical tests with strong correlation with histopathological results would be interesting for veterinarians specially avian specialists[7, 8].

Hepatic lipidosis or fatty liver has been reported in many avian species as well as mammals and humans and it seems to be one of the most prevalent hepatic metabolic disorder in birds $[9,10,11,12,13,14]$. Hepatic lipidosis is not a specific disease entity in birds and many different etiologies like vitamin deficiencies, high energy diets, or even infectious agents could have roles in pathogenesis of fatty liver $[9,2,15,16]$. While case history, clinical signs such as obesity or non-specific signs of hepatic involvement like urate discoloration and biliverdinuria and plasma biochemical analysis could be indicative of lipidosis, but histologic evaluation of biopsy specimens is the most promising technique for definitive diagnosis of hepatic lipidosis $[3,4,5]$. Repeated resampling of the liver biopsy is sometimes needed to monitor the responses to the treatment [17], and it could further put the case in the danger of biopsy complications.

Avian hepatic parenchyma has the same ultrasonographic (US) appearance as mammalian species (Nordberg et al. 2000). As any diffuse changes in normal echogenicity or echotexture could be indicative of diffuse hepatic disorders, US examination is routinely used for diagnosis of fatty liver in human and other mammals $[18,19,20,21]$. The application of a new US elastography technique, acoustic radiation force impulse (ARFI) imaging has been shown to be promising in diagnosis of hepatic lipidosis in chicken in an experimental design [22].

Common mynah (Acridotheres tristis) is a tropical and subtropical bird which is endemic in south and southeast of Iran. It has been also introduced into many regions of the world as an invasive species [23]. Common mynah is a popular pet bird in Iran and hepatomegaly seemed to be the second most frequently observed clinical manifestation in this bird after pododermatitis [24]. Postmortem diagnosis of hepatic lipidosis has been reported in common mynah [13], but same as other avian species antemortem diagnosis of lipidosis is challenging.

In current study the application of three-dimensional Virtual Organ Computer-aided Analysis (VOCAL) US in diagnosis of hepatic lesions especially lipidosis in common mynahs is determined and the result of US evaluation was compared with histopathologic study. The feasibility and capability of the quantitative US examination for presumptive diagnosis of hepatic lipidosis is discussed.

\section{Methods}

The study design and ethical approval was obtained by Faculty of Veterinary Medicine, University of Tehran, Tehran, Iran (1390).

\subsection{Cases}

Referred common mynahs to the pet bird clinic of the Faculty of Veterinary Medicine, University of Tehran during one year with different complaints or clinical signs like anorexia, hepatomegaly diagnosed clinically by 
observation of the liver borders over the abdominal skin, urate discoloration and biliverdinuria suggesting the liver involvement, were selected and included in this study. After the participation in the present study, as a part of diagnostic procedure, the patients received suitable treatment and management based on their clinical conditions in the pet bird clinic.

\subsection{Diagnostic imaging}

Radiography was performed in two projections, lateral (L) and ventrodorsal (VD), using KODAK DIRECTVIEW Classic CR System ( $45 \mathrm{KV}, 0.05 \mathrm{~s}$ ) initially and the images were then evaluated by two non-dependent national board-certified radiologists with more than two years of experience in avian radiology. Detectable hepatomegaly based on deteriorated hourglass appearance associated with expansion of liver shadow from coracoacetabular axis in VD projection and expansion of liver shadow from sternum in $L$ view was used as the radiologic criteria for hepatomegaly (Krautwald-Junghann et al. 2001, Krautwald-Junghann et al. 2011). US examination was performed on the patients with hepatomegaly which had been confirmed by radiography, using GE Voluson 730 Pro unit equipped with multi-frequency $(5-17 \mathrm{MHz})$ linear transducer and 4D linear transducer (6-18 MHz). Conventional US was performed in cranial ventro-median approach from caudal aspect of the sternum in the midline of the body to reduce airsac artifact. Two dimensional US images were evaluated, and qualitative report were recorded, and the cases were ranked from highest to lowest echogenicity, subjectively and objectively. Three-dimensional US data were processed by 4D view®, GE medical system Kertztechnik GmbH \& Co OHG, Version 5.0. VOCAL images and histograms were obtained for region of interest (ROI) with approximate diameter $0.1 \mathrm{~cm}^{3}$ of hepatic tissue and pectoral muscle for comparison in each bird. Mean gray level of liver (MGL), mean gray level of muscle (MGM), relative proportion of mean gray level of liver and muscle (MGR) were calculated and recorded (Table 1, Fig. 1). 
MGL, MGM and MGR of different cases and quantization of pathologic reports

\begin{tabular}{|c|c|c|c|c|c|c|c|c|}
\hline $\begin{array}{l}\text { Number } \\
\text { of } \\
\text { cases }\end{array}$ & $\begin{array}{l}\text { Mean } \\
\text { Gray } \\
\text { of } \\
\text { Liver } \\
\text { (MGL) }\end{array}$ & $\begin{array}{l}\text { Mean } \\
\text { Gray } \\
\text { of } \\
\text { muscle } \\
\text { (MGM) }\end{array}$ & $\begin{array}{l}\text { MGL/MGM } \\
\text { (MGR) }\end{array}$ & Fibroplasia & Hepatitis & ISD & Lipidosis & $\begin{array}{l}\text { Pathologic } \\
\text { report }\end{array}$ \\
\hline No.1 & 32.919 & 17.638 & 1.866 & 0 & 0 & 2 & 1 & $\begin{array}{l}\text { ISD, mild } \\
\text { lipidosis }\end{array}$ \\
\hline No.2 & 28.534 & 25.652 & 1.112 & 0 & 1 & 2 & 0 & Hepatitis, ISD \\
\hline No.3 & 29.286 & 28.180 & 1.039 & 0 & 0 & 1 & 2 & $\begin{array}{l}\text { Hemosidrosis, } \\
\text { moderate } \\
\text { lipidosis }\end{array}$ \\
\hline No.4 & 32.497 & 39.361 & 0.826 & 1 & 0 & 0 & 3 & $\begin{array}{l}\text { Sever } \\
\text { lipidosis, } \\
\text { fibroplasia }\end{array}$ \\
\hline No.5 & 43.251 & 24.150 & 1.791 & 0 & 1 & 2 & 0 & Hepatitis, ISD \\
\hline No.6 & 45.261 & 36.180 & 1.251 & 0 & 0 & 0 & 0 & $\begin{array}{l}\text { Very low } \\
\text { vacuolization } \\
\text { (not } \\
\text { significant) }\end{array}$ \\
\hline No.7 & 21.126 & 16.472 & 1.283 & 1 & 0 & 0 & 1 & $\begin{array}{l}\text { Mild lipidosis, } \\
\text { fibroplasia }\end{array}$ \\
\hline No.8 & 13.749 & 25.754 & 0.534 & 0 & 1 & 0 & 2 & $\begin{array}{l}\text { Hepatitis, } \\
\text { moderate } \\
\text { lipidosis }\end{array}$ \\
\hline No.9 & 12.782 & 33.328 & 0.384 & 0 & 0 & 0 & 3 & $\begin{array}{l}\text { Sever } \\
\text { lipidosis }\end{array}$ \\
\hline No.10 & 24.786 & 39.802 & 0.623 & 0 & 0 & 1 & 3 & $\begin{array}{l}\text { Sever } \\
\text { lipidosis, } \\
\text { hemosidrosis }\end{array}$ \\
\hline No.11 & 23.666 & 13.223 & 1.790 & 0 & 0 & 0 & 0 & N/A \\
\hline
\end{tabular}

\subsection{Biopsy and histopathology}

Fine-needle tissue core biopsy were taken under ultrasound guide using G18 needle biopsy gun. The birds were sedated with intramascular injection of Ketamin $(20 \mathrm{mg} / \mathrm{kg})$ and diazepam $(1 \mathrm{mg} / \mathrm{kg})$. No complications were observed after biopsy. Biopsy samples were fixed in 10\% buffered formalin and thin histologic sections were prepared with haematoxylin and eosin staining (H\&E). Blind histopathological examination was done and results altered to scale ranking for each disorder independently, no sign of hepatocytes vacuolation and fatty changes $=0$, mild vacuolation of hepatocytes (mild fatty change) $=1$, moderate vacuolation of hepatocytes $=2$, sever vacuolation of hepatocytes (hepatic lipidosis) $=3$; no sign of iron storage and hemosiderosis $=0$, 
hemosiderosis $=1$, severe hemosiderosis and iron storage $=2$; no sign of hepatitis $=0$, hepatitis $=1$; fibroplasia $=$ 1 , No sign of fibroplasia $=0$ (Table 1$)$.

\subsection{Statistical analysis}

Quantitative results from US evaluation were then compared with histopathological results for each patients and statistical examination (Tukey, Kruskal-Wallis) was performed. Subjective and objective arrangement of the cases from highest to lowest echogenisity were compared to each other by $\mathrm{k}$ test. All the statistics were evaluated by SPSS (SPSS for Windows, Release 13.0, standard version, SPSS, Inc., Chicago, IL.).

\section{Result}

Totally, eleven birds were included in this study based on clinical and radiologic manifestations. Median age (if not applicable the duration of ownership) of the birds was 24 months ranging from 13 to 144 months. Age of the birds was not significantly correlated with MGL $(r=0.14$ and $p=0.78), \operatorname{MGM}(r=-0.45$ and $p=0.25)$, and $\operatorname{MGR}(r=0.38$ and $p=0.35)$ (Table 1$)$.

MGR in the patients were significantly different among groups with different degree of lipidosis $(p=0.02)$; however, no significant difference was observed in MGL or MGM among the groups ( $p=0.39$ and 0.05, respectively). Further post-hoc analysis revealed that MGR in patients with no or slight lipidosis was significantly higher than patients with moderate or severe lipidosis lesions ( $p=0.04$ and 0.01 , respectively). No other significant differences were evident in MGR among these groups $(p<0.05)$ (Fig. 2A).

No significant difference was observed in MGL, MGM, and MGR among patients with different level of iron storage or hemosiderosis ( $p=0.43,0.43$, and 0.20 , respectively) (Fig. 2B) and in patients with and without fibroplasia in terms of MGL, MGM, and MGR ( $p=0.87,0.91$, and 0.82 , respectively). Similarly, no significant difference was noticeable in patients with and without hepatitis regarding the MGL, MGM, and MGR ( $p=0.92$, 0.67 , and 0.97 , respectively) (Fig. 2C and 2D).

Subjective and objective arrangement of the cases based on 2D US obtained echogenicities were just matched at the minimum and maximum limits and no significant association was detected statistically.

\section{Discussion}

Diagnosis of liver diseases in bird is challenging as other animals. Valuable diagnostic information can be gathered using US. In the present study the feasibility and capability of using 3D VOCAL US for etiologic diagnosis of liver disorders in common mynahs were evaluated. Eleven mynahs with clinical and radiographic signs of hepatomegaly were evaluated by US and their liver biopsy samples were histologically investigated. Different minor to major pathologic changes were diagnosed in these birds. MGR of two different quantitative measurements including MGL MGM was associated with moderate to severe hepatic lipidosis. On the other hand, quantitative 3D VOCAL US evaluation was not capable of diagnosis of iron storage, hepatitis, and fibroplasia of the liver.

The diagnosis of diffuse changes in hepatic parenchyma is conventionally based on the subjective assessment of liver echogenicity $[5,25]$. Evaluation of the liver by US is highly operator dependent. Although quantitative 
methods for measuring tissue echogenicity have been reported in human, these methods are not yet widely applied in avian practice [26,27]. Display and formation of images in US are related to the tissue characterization, thus objective evaluation is useful to assess any changes consists in differentiating subtle changes in ultrasound speckle patterns, which may remain perceptible to human visual inspection [28]. Overall, the quantification is an objective evaluation of these changes and pathological state of the tissue by medical imaging that is helpful in diagnosing the disease. Research has currently focused on suggesting non-invasive methods to diagnose fatty liver as an alternative to liver biopsy. Several methods such as CT, MRI and acoustic radiation force impulse (ARFI) imaging are presented as potential methods for objective evaluation of the liver based on the changes of the tissue microstructures $[22,29]$.

The echogenicity of some parenchymatous organs such as spleen or kidneys are usually used as reference for comparing them to the liver in mammalian species [30]. These reference organs are not easily accessible in avian species due to their special anatomic adaptation [5]. The heart or vessels were suggested in avian patient for comparison [5]. According to its good accessibility, the pectoral muscle mass was used in the present study for this purpose and the result was promising.

The liver biopsy, its histologic evaluation and also microbiological culture are often necessary for definitive diagnosis of hepatic disorders $[4,5,25]$. Taking liver biopsy is a painful technique and despite the local anesthesia, the pain was retained in human patient at least 24 hours post procedure [31]. It should be considered that avian patient with hepatic disorders have less tolerance facing with stress and many birds are commonly presented in a poor condition [32]. While no complications were observed in our cases, massive internal hemorrhage could be the other adverse consequence of core needle liver biopsy in birds considering the possible coagulopathy in hepatic diseases $[33,34]$. The absence of commercial test for routine coagulation determination in avian species further limit the safety of biopsy taking in birds [1, 4]. In this situation any alternative non-invasive diagnostic technique could be helpful in severely sick and debilitated avian patients.

As our results showed there was no correlation between fibrosis and US characteristics of the liver. Interestingly it was shown that sound attenuation in human liver with connective tissue proliferation was also minimal to undetectable. In agreement with our result, more attenuation has been detected in human cases with domination of fat in the hepatic tissue [35]. In conclusion at least severe lipidosis can be presumptively diagnosed by US relying on different sound interaction in fatty liver [35]. Lu et al. (1997) showed that quantitative US is more sensitive than subjective evaluation in the detection of initial phase of diffuse liver pathologies including the accumulation of fat [36].

Water content of the liver in rats suffered from fatty liver and cirrhosis did not correlate with the sound speed. On the other hand, the nature of hepatic tissue including the fat content and cirrhosis were associated with the sound speed. Echogenicity alteration was obvious in fatty liver, but no significant differences were detectable among the different degrees and stages of the lipidosis in affected rats [37]. Furthermore, in another study, the quantitative US has been shown to be a feasible and efficient method for detection and follow up of the hepatic lipidosis and subjective US was a practical replacement for histopathological examination [38]. Therefore, in compliance with our study higher hepatic fat content made the liver brighter in US evaluation, while the normal appearance is the result of collagen and the water content [39]. 
In agreement with our result in the field of avian practice, quantitative US was also applied as a noninvasive technique for monitoring of hepatic lipidosis in dairy cattle [40,41]. Digitalized analysis of the liver US images was shown to be a promising noninvasive screening technique for fatty liver detection in dairy herd [27].

Multiple factors including depth related attenuation of the measured area and concurrent fibrosis and fatty infiltration might influence quantitative US diagnosis [42].

However, increase in liver echogenicity is expected in several vacuolar diseases; Lu et al. showed that elevation of the attenuation and backscatter coefficients in fatty liver was greater than cirrhotic liver [43]. Regarding the relatively small liver size in passerines, the impact of the chosen ROI could be minimal or even negligible in these birds.

Matheson et al. (2007) presented no significant change in pixel intensity of the US images in pigeon's hemosiderosis that is same as results of the present study [44]. Different signal intensity is reported in the different iron content of human liver as compared to the muscle and pigeon's hepatic iron content using magnetic resonance imaging (MRI) $[45,46]$. Thus, MRI seems to be prior to US for the detection of iron deposition in the liver.

Small sample size and lack of normal group in the present study was considered as limitations. These limitations are unavoidable in the field of exotic animal research. Thus, further validation and comparison with normal livers to suggest cut-off values are needed in patients and normal population.

\section{Conclusion}

Based on qualitative and quantitative evaluation of hepatic echogenicity in the present study, quantitative evaluation was suggested for definitive evaluation of hepatic parenchyma. This study revealed that only MGR could be applicable in the diagnosis of hepatic lipidosis. In conclusion, application of VOCAL three-dimensional ultrasonography and evaluation of MGR can be helpful in diagnosis and monitoring of moderate to severe liver lipidosis in birds and maybe used in the other species as well.

\section{Abbreviations}

2D

Two-dimensional

3D

Three-dimensional

4D

Four-dimensional

ARFI

acoustic radiation force impulse

CT

Computed tomography

H\&E

haematoxylin and eosin staining 
Lateral

MGL

Mean gray level of liver

MGM

Mean gray level of muscle

MGR

relative proportion of $M G L$ and MGM

MRI

Magnetic resonance imaging

ROI

region of interest

US

Ultrasonography

VD

Ventrodorsal

VOCAL

Virtual Organ Computer-aided Analysis

\section{Declarations}

\section{Ethics approval and consent to participate}

The study design and ethical approval was obtained by Faculty of Veterinary Medicine, University of Tehran, Tehran, Iran.

\section{Consent for publication}

The owners of the included birds were informed about and agreed to participate in this study.

\section{Competing interests}

No competing interests

\section{Funding}

This research has no funding.

\section{Authors' contributions}

All authors have read and approved the manuscript

YV: Study design, data acquisition, analysis, drafting of the manuscript, finalizing the manuscript. MM: Study design, data approval, SS: Study design, data approval, SAM: Study design, data acquisition, data approval, drafting of the manuscript, finalizing the manuscript, $\mathrm{MH}$ : Study design, consultation. 
Acknowledgements

No acknowledgements

\section{References}

1. Lumeij JT. Hepatology. In: Ritchie BW, Harrison GJ, Harrison LR, editors. Avian Medicine, Principles and Application. Lake Worth: Wingers Publishing; 1994. pp. 522-37.

2. Davies RR. Avian liver disease: etiology and pathogenesis. InSeminars in Avian and Exotic Pet Medicine 2000, (Vol. 3, No. 9, pp. 115-125).

3. Jaensch S. Diagnosis of avian hepatic disease. In Seminars in avian and exotic pet medicine 2000, Jul 1 (Vol. 9, No. 3, pp. 126-135). WB Saunders.

4. Grunkemeyer VL: Advanced diagnostic approaches and current management of avian hepatic disorders. Veterinary Clinics: Exotic Animal Practice. 2010, Sep 1;13(3):413 - 27.

5. Krautwald-Junghanns ME, Zebisch K, Enders F, Pees M, Willuhn: Diagnosis of liver disease in birds by radiography and ultrasonography: under special consideration of ultrasound-guided liver biopsies. In Seminars in Avian and Exotic Pet Medicine. 2001 WB Saunders pp 153-161.

6. Nordberg C, O'BRIEN RT, Paul-Murphy J, Hawley B. Ultrasound examination and guided fine-needle aspiration of the liver in Amazon parrots (Amazona species). Journal of Avian Medicine Surgery. 2000 Sep;14(3):180-4.

7. Fierbinteanu-Braticevici C, Dina I, Petrisor A, Tribus L, Negreanu L, Carstoiu C. Noninvasive investigations for non-alcoholic fatty liver disease and liver fibrosis. World Journal of Gastroenterology: WJG. 2010 Oct;14(38):4784. 16(.

8. Wieckowska A, McCullough AJ, Feldstein AE. Noninvasive diagnosis and monitoring of nonalcoholic steatohepatitis: present and future. Hepatology. 2007 Aug;46(2):582-9.

9. Butler EJ. Fatty liver diseases in the domestic fowl-A review. Avian Pathology. 1976 Jan 1;5(1):1-4.

10. Wadsworth PF, Jones DM, Pugsley SL: Fatty liver in birds at the zoological society of London. Avian Pathology. 1984 Apr 1;13(2):231-9.

11. Forbes NA, Cooper JE. Fatty liver-kidney syndrome of merlins. In: Raptor biomedicine 1993 (pp. 45-48). University of Minnesota Press Minneapolis, MN.

12. Langlois I, Jones MP. Ventral abdominal hernia associated with hepatic lipidosis in a red lory (Eos bornea). J Avian Med Surg. 2001;15(3):216-23.

13. Madani SA, Hatamkhani A, Soroori S. Hepatic lipidosis in a common mynah (Acridotheres tristis) associated with pododermatitis and consumption of broiler pelleted feed. IJVM. 2012;6(4):279-83.

14. Beaufrère H, Reavill D, Heatley J, Susta L. Lipid-Related Lesions in Quaker Parrots (Myiopsitta monachus). Vet Pathol. 2019;56(2):282-8.

15. Hochleithner M, Hochleithner C, Harrison LD: Evaluating and treating the liver. In Clinical avian medicine, G.J. Harrison \& T.L. Lightfoot, editors. Spix publishing, Palm Beach, Florida, 2006: pp 441-450.

16. Schmidt RE, Reavill DR, Phalen DN. Pathology of pet and aviary birds. lowa: John Wiley \& Sons. Ames; 2015. pp. 95-127. 
17. Redrobe S. Treatment of avian liver disease. In Seminars in Avian and Exotic Pet Medicine, 2000, $136-145$.

18. Hepburn MJ, Vos JA, Fillman EP, Lawitz EJ. The accuracy of the report of hepatic steatosis on ultrasonography in patients infected with hepatitis $C$ in a clinical setting: a retrospective observational study. BMC Gastroenterol. 2005;5(1):14.

19. Schwenzer NF, Springer F, Schraml C, Stefan N, Machann J, Schick F. Non-invasive assessment and quantification of liver steatosis by ultrasound, computed tomography and magnetic resonance. $\mathrm{J}$ Hepatol. 2009;51(3):433-45.

20. Hernaez R, Lazo M, Bonekamp S, Kamel I, Brancati FL, Guallar E, Clark JM. Diagnostic accuracy and reliability of ultrasonography for the detection of fatty liver: a meta-analysis. Hepatology. 2011;54(3):1082-90.

21. Taibbi A, Picone D, Midiri M, La Grutta L, Bartolotta TV: Diffuse Liver Diseases: Role of imaging. In Seminars in Ultrasound, CT and MRI. WB Saunders, 2018, 193-205.

22. Aroca FG, Ayala I, Serrano L, Berná-Serna JD, Castell MT, García-Pérez B, Reus M. Assessment of liver steatosis in chicken by using acoustic radiation force impulse imaging: preliminary results. Eur Radiol. 2010;20(10):2367-71.

23. Holzapfel C, Levin N, Hatzofe O, Kark S. Colonisation of the Middle East by the invasive Common Myna Acridotheres tristis L., with special reference to Israel. Sandgrouse. 2006;28(1):44.

24. Madani SA, Eram N, Rezaeifar A, Arabkhazaeli F. Common diseases of common mynah (Acridotheres tristis): frequently observed pathologies in referred cases. In J. Chitty, editor, Proceedings of the 1st International Conference on Avian Herpetological and Exotic Mammals Medicine, 2013, Wiesbaden, Germany. Gissen:VVB Laufersweiler Verlag, pp 410.

25. Krautwald-Junghanns ME, Schmidt V. Special diagnostic, pathological findings Diagnostic imaging of exotic pets: birds, small mammals, reptiles. Aust Vete J. 2011;89(10):408-8.

26. Zwiebel WJ: Sonographic diagnosis of diffuse liver disease. In Seminars in Ultrasound, CT and MRI. WB Saunders, 1995: 8-15.

27. Starke A, Haudum A, Weijers G, Herzog K, Wohlsein P, Beyerbach M, Rehage J. Noninvasive detection of hepatic lipidosis in dairy cows with calibrated ultrasonographic image analysis. J Dairy Sci. 2010;93(7):2952-65.

28. İçer S, Coşkun A, İkizceli T. Quantitative grading using grey relational analysis on ultrasonographic images of a fatty liver. J Med Syst. 2012;36(4):2521-8.

29. Xu L, Duanmu Y, Blake GM, Zhang C, Zhang Y, Brown K, Wang C. Validation of goose liver fat measurement by QCT and CSE-MRI with biochemical extraction and pathology as reference. Eur Radiol. 2018;28(5):2003-12.

30. Nyland TG, Park RD. Hepatic ultrasonography in the dog. Vet Radiol. 1983;24(2):74-84.

31. Eisenberg E, Konopniki M, Veitsman E, Kramskay R, Gaitini D, Baruch Y. Prevalence and characteristics of pain induced by percutaneous liver biopsy. Anesth Analg. 2003;96(5):1392-6.

32. Zebisch K, Krautwald-Junghanns ME, Willuhn J. Ultrasound-guided liver biopsy in birds. Vet Radiol Ultrasound. 2004;45(3):241-6.

33. Hong WD, Zhu QH, Huang ZM, Chen XR, Jiang ZC, Xu SH, Jin K. Predictors of esophageal varices in patients with HBV-related cirrhosis: a retrospective study. BMC Gastroenterol. 2009;9(1):11. 
34. Hager DA, Nyland TG, Fisher P. Ultrasound-guided biopsy of the canine liver, kidney, and prostate. Vet Radiol. 1985;26(3):82-8.

35. Szebeni A, Tolvaj G, Zalatnai A. Correlation of ultrasound attenuation and histopathological parameters of the liver in chronic diffuse liver diseases. Eur J Gastroenterol Hepatol. 2006 Jan;18(1)(1):37-42.

36. Lu ZF, Zagzebski JA, O'Brien RT, Steinberg H. Ultrasound attenuation and backscatter in the liver during prednisone administration. Ultrasound Med Biol. 1997;23(1):1-8.

37. Matsuhashi T, Yamada N, Shinzawa H, Takahashi T. An evaluation of hepatic ultrasound speed in injury models in rats: correlation with tissue constituents. J Ultrasound Med. 1996;15(8):563-70.

38. Lessa AS, Paredes BD, Dias JV, Carvalho AB, Quintanilha LF, Takiya CM, ... Goldenberg RC: Ultrasound imaging in an experimental model of fatty liver disease and cirrhosis in rats. BMC Vet Res 2010, 6(1): 6.

39. Joseph AEA, Dewbury KC, McGuire PG. Ultrasound in the detection of chronic liver disease (the "bright liver"). Brit J Radiol. 1979;52(615):184-8.

40. Acorda JA, Yamada H, Ghamsari SM. Evaluation of fatty infiltration of the liver in dairy cattle through digital analysis of hepatic ultrasonograms. Vet Radiol Ultrasound. 1994;35(2):120-3.

41. Bobe G, Amin VR, Hippen AR, She P, Young JW, Beitz DC. Non-invasive detection of fatty liver in dairy cows by digital analyses of hepatic ultrasonograms. J DAIRY Res. 2008;75(1):84-9.

42. Garra BS: In vivo liver and splenic tissue characterization by scattering. In Ultrasonic scattering in biological tissues. CRC Press, 1993, 347-392.

43. Lu ZF, Zagzebski JA, Lee FT. Ultrasound backscatter and attenuation in human liver with diffuse disease. Ultrasound Med Biol. 1999;25(7):1047-54.

44. Matheson JS, Paul-Murphy J, O'Brien RT, Steinberg H. Quantitative ultrasound, magnetic resonance imaging, and histologic image analysis of hepatic iron accumulation in pigeons (Columbia livia). Journal of Zoo Wildlife Medicine. 2007 Jun;38(2):222-30.

45. Ernst O, Sergent G, Bonvarlet P, Canva-Delcambre V, Paris JC. L'Herminé C: Hepatic iron overload: diagnosis and quantification with MR imaging. AJR. 1997;168(5):1205-8.

46. Simchick G, Liu Z, Nagy T, Xiong M, Zhao Q: Assessment of MR-based and quantitative susceptibility mapping for the quantification of liver iron concentration in a mouse model at 7T. Magn Reson Med 2018, 80(5): 2081-2093.

\section{Figures}



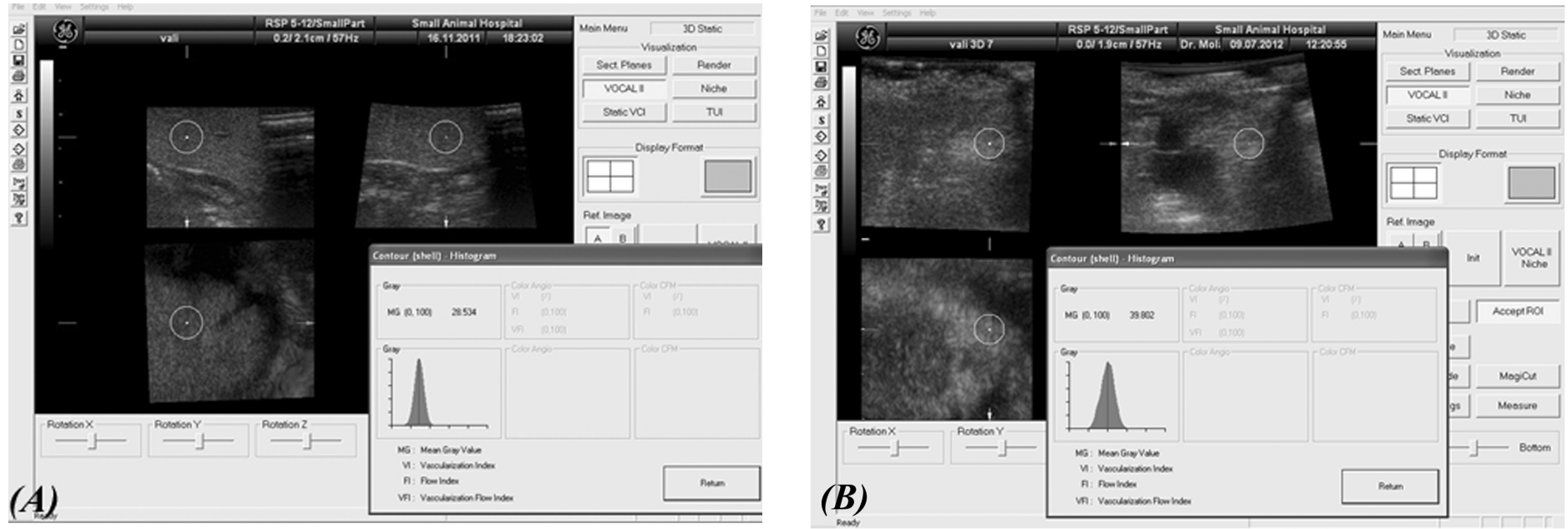

Figure 1

VOCAL picture and histogram for region of interest (ROI) with approximate diameter $0.1 \mathrm{~cm}$ of hepatic tissue (A) and pectoral muscle (B).
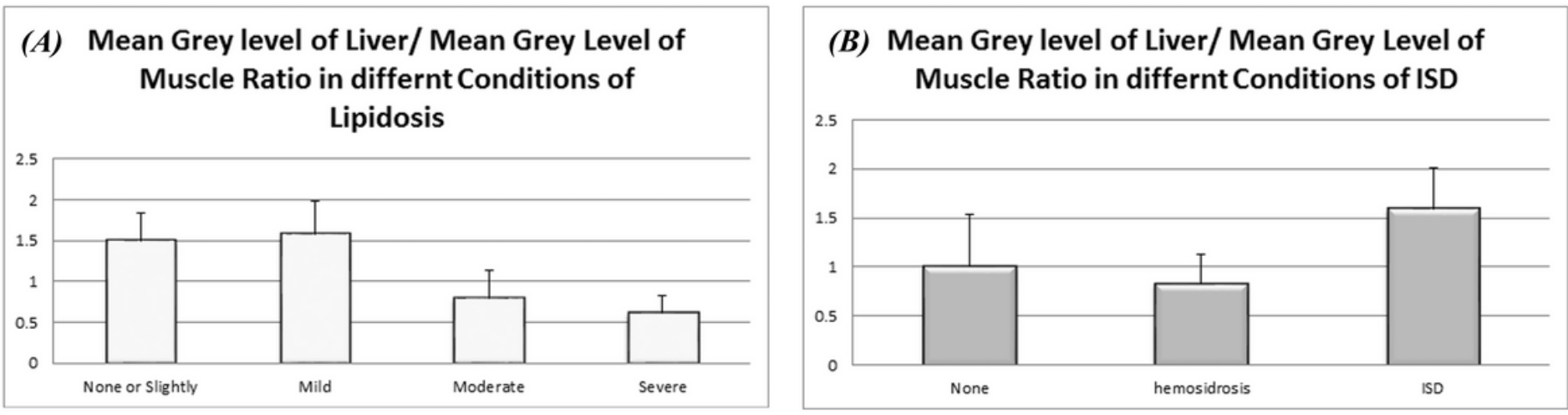

\section{(C) Mean Grey level of Liver/ Mean Grey Level of Muscle Ratio in Patients With and Without \\ Fibroplasia}

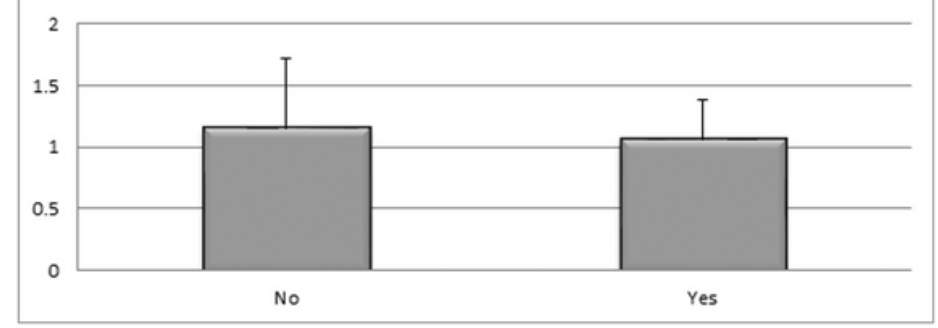

(D) Mean Grey level of Liver/ Mean Grey Level of Muscle Ratio in Patients With and Without Hepatitis

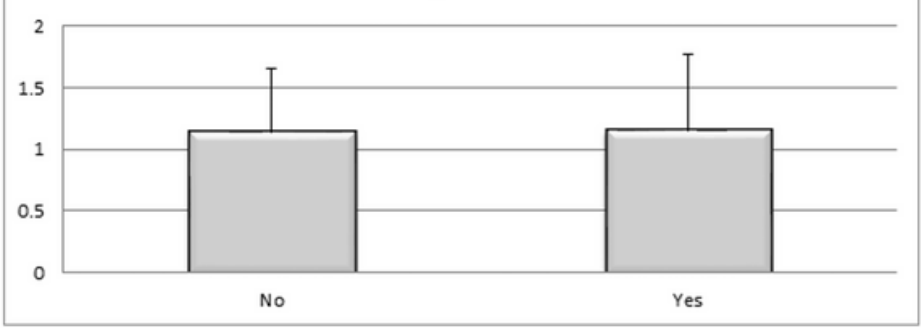

\section{Figure 2}

(A) Mean gray level of the liver/ Mean gray level of muscle ratio in different conditions of lipidosis. (B) Mean gray level of the liver/ Mean gray level of muscle ratio in different conditions of ISD. (C) Mean gray level of the liver/ Mean gray level of muscle ratio in patients with and without fibroplasia. (D) Mean gray level of the liver/ Mean gray level of muscle ratio in patient with or without hepatitis. 


\section{Supplementary Files}

This is a list of supplementary files associated with this preprint. Click to download.

- Arrivechecklist.PDF 